\title{
A procedure for estimating wind waves and storm-surge climate scenarios in a regional basin: the Adriatic Sea case
}

\author{
P. Lionello ${ }^{1, *}$, A. Nizzero ${ }^{2}$, E. Elvini ${ }^{2}$ \\ ${ }^{1}$ Dept of Science of Materials, University of Lecce, via per Arnesano, 73100 Lecce, Italy \\ ${ }^{2}$ Dept of Physics, University of Padua, via F. Marzalo 8, 35131 Padua, Italy
}

\begin{abstract}
This study attempts to estimate the effect of $\mathrm{CO}_{2}$ doubling on the frequency and intensity of high wind waves and storm-surge events in the Adriatic Sea. The meteorological forcings were derived from two 30-yr-long time-slice experiments that simulated the global atmospheric circulation in the present and the doubled- $\mathrm{CO}_{2}$ climate scenarios. These time-slice experiments were carried out by the Danish Meteorological Institute using the ECHAM-4 model at T106 resolution. Unfortunately, the resolution of the T106 wind is inadequate for simulation of the wave field and the storm surge in the Adriatic Sea, and it results in a gross underevaluation of extreme events. In this study, regional surface wind fields have been derived from T106 sea-level-pressure fields by statistical downscaling. Downscaled wind fields have been used to force a wave and an ocean model during the two 30 -yrlong simulations. The downscaled wind fields produce a large improvement with respect to the T106 fields, but a systematic underestimation with respect to the observed wave height and surge levels remains present. This shortcoming of the analysis might prevent identification of very intense events. Consequently, extreme-value analysis of the results of the present climate simulation produces values lower than observed, and obviously the same systematic bias is expected in the evaluation of the future climate. Some caution is therefore necessary in the interpretation of the results of this study. Nonetheless, the comparison between the present and future climate simulations shows no substantial change in the extreme surge level and a decrease in the extreme wave height.
\end{abstract}

KEY WORDS: Regional climate scenarios $\cdot$ Storm surges $\cdot$ Wave height $\cdot$ Extremes $\cdot \mathrm{CO}_{2}$ doubling

\section{INTRODUCTION}

This study is the first attempt to evaluate the effect of the doubling of the atmospheric $\mathrm{CO}_{2}$ content on extreme storm surges and wind waves in the Adriatic Sea. The results are particularly important for the Venetian littoral, the flat northern coast of the Adriatic Sea, which is particularly vulnerable to storm surges and high wave conditions. An intensification or a variation of the present characteristics of the marine storms in this area could necessitate the reorganization of the coastal defense for the protection of an economically important area and a unique historical and environmental heritage.

The input information for this analysis has been obtained from two 30-yr long time-slice experiments carried out with the ECHAM-4 model at the Danish
Meteorological Institute (DMI) and simulating the global atmospheric circulation: a CTR (control) experiment, which reproduces the present climate, and a $\mathrm{CO}_{2}$ experiment, which simulates the effect of a doubled atmospheric $\mathrm{CO}_{2}$ content (May 1999). The $\mathrm{CO}_{2}$ experiment is based on an updated IS92a scenario (IPCC 1994), including, besides $\mathrm{CO}_{2}$, methane, nitrous oxide and several industrial gases. Both experiments were carried out at T106 resolution, corresponding to a $160 \times 320$ global Gaussian grid, with 19 vertical levels . An explicit goal of this experiment was to provide information for regional climate-change studies. Although the T106 resolution is high for a global climate simulation, it is inadequate for the reproduction of the surface wind fields in the Adriatic Sea. When transferred to a latitude-longitude grid corresponding to this resolution, the whole T106 wind field in the Adri- 
atic Sea is represented by approximately 10 grid points, and there is a very poor reproduction of the deformation of the wind flow due to the mountain ridges surrounding the basin. Therefore, it is not possible to use directly the T106 wind fields, and a downscaling procedure is necessary for the computation of the storm surges and the wave fields.

The approach adopted in this study exploits the relationship between SLP (sea-level pressure) and surface wind in order to derive the wind fields with a $0.25^{\circ}$ resolution in the Adriatic Sea from the SLP fields at T106 resolution. The downscaled (regional) wind fields are used as common input for the barotropic shallow water model (HYPSE, Hydrostatic Padua Sea surface Elevation model), which predicts the surge level, and the third generation WAM model (WAve Model, WAMDI Group 1987), which predicts the wave spectrum. HYPSE is a standard barotropic model in curvilinear coordinates whose numeric is similar to the external mode of the well-known POM (Princeton Ocean Model, Blumberg \& Mellor 1987) coastal model, but it includes the SLP forcing and the astronomical tide. HYPSE and WAM have already been successfully used in the prediction of wave heights and surge levels in the Adriatic Sea (e.g. Lionello et al. 1998).

This procedure has been applied to 2 types of simulations: hindcasts and scenario simulations. There are 2 scenario simulations: the CTR simulation, reproducing the present climate, and the $\mathrm{CO}_{2}$ simulation, reproducing the doubled- $\mathrm{CO}_{2}$ scenario. The purpose of the hindcasts is to validate the procedure, showing its potential and limitations. The purpose of the scenarios is to investigate the presence of a climate-change signal in waves and surge levels in the Adriatic Sea. When the input SLP is extracted from the ERA-15 dataset (ECMWF 15 yr reanalysis; Gibson et al. 1996), the computed wave and sea-surface elevation fields are the result of a hindcast study which can be compared to the observations and used for the validation of this procedure. When the input SLP fields are produced by the time-slice experiments of the $\mathrm{CO}_{2}$ and CTR climate scenarios, the resulting wave and sea-surface elevation fields are simulations of the regional (Adriatic) wave and surge scenarios, which are used for the climate-change analysis.

This paper is organized in the following way. Section 2 describes the statistical downscaling of the wind fields and the whole procedure for the computation of wave fields and surge levels. Section 3 describes a set of hindcast studies for the validation of the downscaling procedure against wave and surge observations. Section 4 describes the results of the scenario simulations and of the extreme value analysis for the surge level (Section 4.1) and for the SWH (significant wave height; Section 4.2). A major limitation of the down- scaling procedure is that there is no compensation for the low time resolution used for the output of the largescale fields and a well-known tendency to produce smooth space-time distributions. The importance of these effects is analyzed in Section 4.3. The outcomes of the study are summarized in Section 5.

\section{THE DOWNSCALING PROCEDURE}

The quality of the surface wind fields is a crucial element for the accurate reproduction of the storm surge and of the wave fields, because the wind fields represent the common forcing for both models. The surge level depends also on the SLP field, though this plays a minor role in the shallow northern part of the Adriatic Sea. Moreover, the SLP is expected to be well reproduced at T106 resolution. Therefore no downscaling of the SLP fields was carried out, and the SLP fields at T106 resolution were simply interpolated on the grid of the shallow-water model.

The downscaling procedure uses, as predictor, the SLP values interpolated on a regular latitude-longitude grid with a resolution of approximately $1.1^{\circ}$, covering the area $10.1^{\circ} \mathrm{W}-40.5^{\circ} \mathrm{E}, 25.3-52.1^{\circ} \mathrm{N}$, and it produces, as predictand, the wind fields on a regular grid, with a resolution of $0.25^{\circ}$, covering the area $11.25-20.0^{\circ} \mathrm{E}, 38.0-46.0^{\circ} \mathrm{N}$. The areas of predictor and predictand are shown in Fig. 1.

The downscaling of the wind fields follows a standard procedure based on the CCA (canonical correlation analysis) of the fields prefiltered using PCA (principal component analysis). An exhaustive description can be found in Bretherton et al. (1992). The procedure (shown in Fig. 2) includes a prefiltering of both predictor and predictand fields based on PCA. CCA of the T106 SLP fields and the regional wind fields produces the canonical maps and the correlation coefficients for the prediction of the downscaled winds from the whole time series of the T106 SLP fields. In order to make available both the T106 SLP fields and the corresponding regional (high resolution) wind fields, a set of events was simulated at a resolution of $0.25^{\circ}$ with the meteorological model BOLAM (BOlogna Limited Area Model; Buzzi et al. 1994). The downscaled wind fields are used by HYPSE and WAM to produce the regional SSE (seasurface elevation) and SWH fields. The WAM model and HYPSE were implemented at $1 / 6^{\circ}$ and $1 / 12^{\circ}$ resolution, respectively, in the same area were the downscaled wind fields were computed. Therefore the whole procedure results in the computation of high-resolution SWH and SSE fields over a regional domain using, as input, a series of low-resolution (global) SLP fields.

The computation of the downscaled wind fields is a fundamental intermediate step of the downscaling 


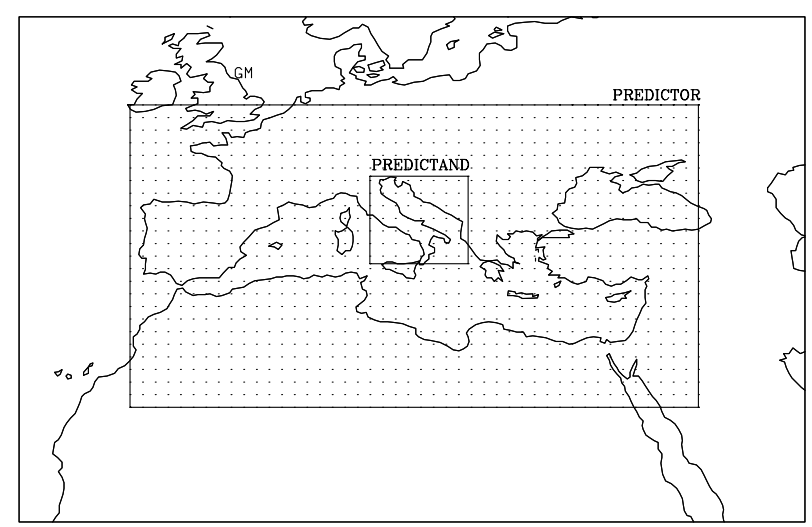

Fig. 1. The rectangle over Europe shows the area covered by the SLP (sea-level pressure) fields (predictor) and the smaller rectangle over the Adriatic Sea shows the area covered by the surface wind fields (predictand)

procedure. This approach was chosen over direct statistical downscaling of the SWH and SSE fields, because both fields contain components that are not related to the instantaneous SLP field, but depend on its previous history. The sea-surface oscillations in the Adriatic Sea include large seiches, whose energy is slowly dissipated, with a $10 \%$ decrement at each oscillation. The wave fields include a swell component, which is particularly large for waves traveling along the main axis of the basin or entering it from the Ionian Sea. The simulations carried out with WAM and HYPSE covered most of the Ionian Sea in order to eliminate border effects. In this way, as far as waves are concerned, the swell entering the Adriatic Sea through the Otranto Strait is included in the simulation. As far as surge is concerned, the part of the inverse barometric effect associated with SLP differences between the Ionian Sea and the Adriatic Sea is included. Largerscale SSE variations involving the whole Mediterranean Sea are not simulated but partially included, by imposing the value given by the inverse barometric effect at the southern open boundary.

The PCA prefiltering is a usual procedure for the reduction of the noise in the signal. Fig. 3 shows the percentage of explained variance for the SLP and wind fields as a function of the number of EOFs (empirical orthogonal functions) considered. It shows that, even at the regional scale of the Adriatic Sea, the wind field has more degrees of freedom than the SLP field. After some tests, the prefiltering was carried out, and only 14 components for the SLP fields and 20 components for the wind fields were retained. With this selection, an explained variance level well above 95\% for both fields was obtained (see Fig. 3). The larger number of components needed to describe the wind fields, with
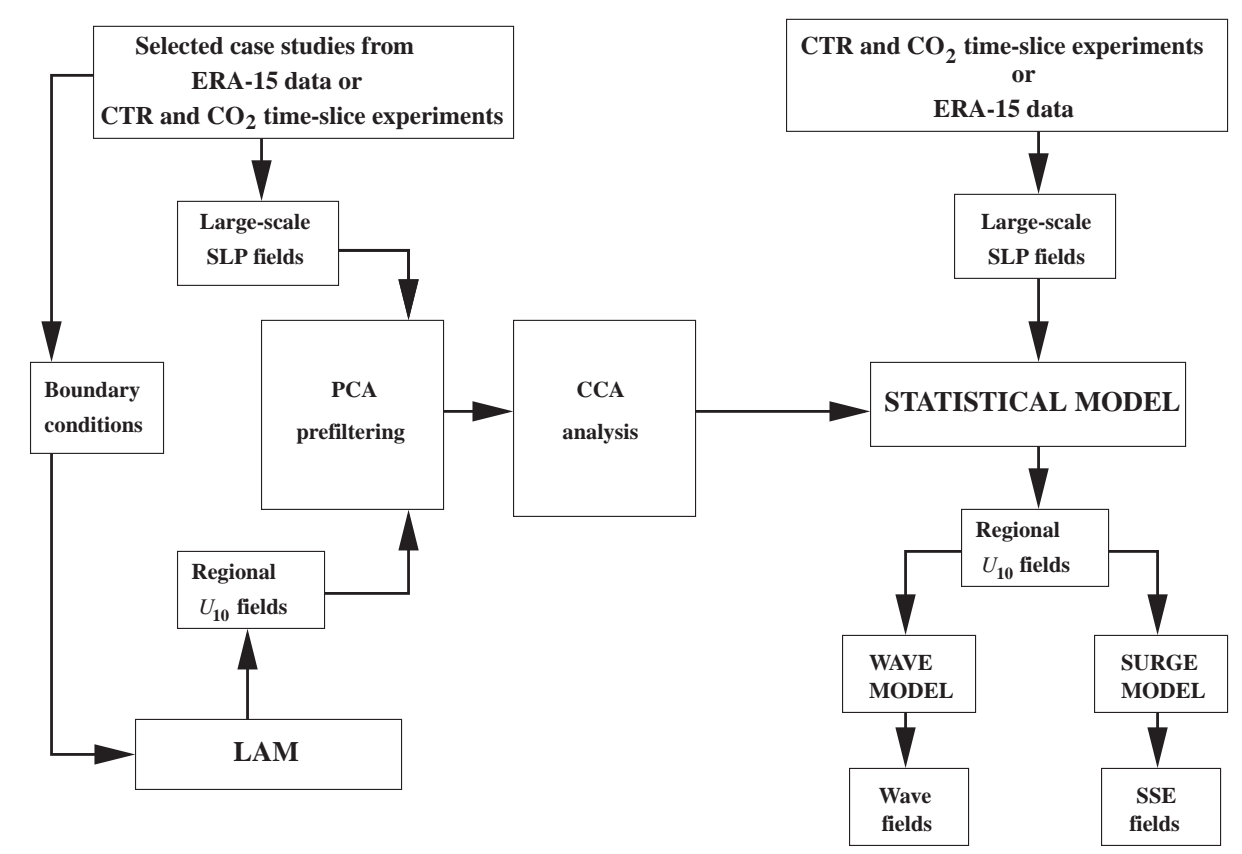

Fig. 2. Downscaling procedure used for the computation of the regional wind fields. Both wind and SLP fields are prefiltered using PCA (principal component analysis). The CCA (canonical correlation analysis) of the T106 SLP fields and the regional wind fields produces the canonical maps and the correlation coefficients, i.e. it produces the statistical model that is used for the prediction of the downscaled winds from the whole time series of the T106 SLP fields. The downscaled wind fields are used by

WAM and HYPSE to produce the regional SSE (sea-surface elevation) and wave fields. LAM: limited-area model 


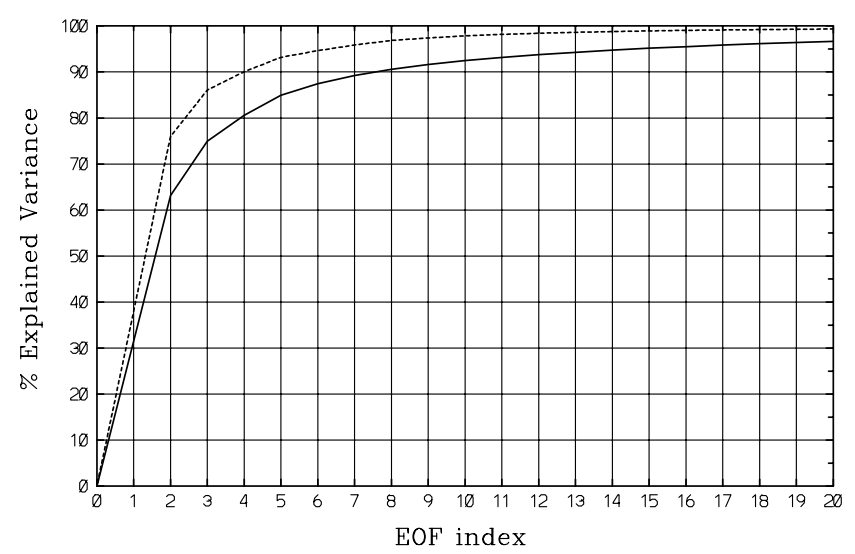

Fig. 3. Cumulative explained variance as a function of the number of EOF (empirical orthogonal function) components used in the PCA for the SLP (dashed line) and the wind fields (solid line)

respect to the SLP fields, is likely explained by the higher resolution of the regional model used for their computation and by the additional variability due to the interaction between the atmospheric circulation and the steep orography of the Mediterranean region.

Fig. 4 shows the first 3 pairs of canonical maps. Note that a vector formalism was used for the canonical maps of the wind fields. The contour lines plotted in the figures denote the magnitude of the resulting vectors. In Fig. 4, the maps were normalized to their maximum value. The strong deviation of the wind vectors from the geostrophy shows the important role of the orography in the deformation of the wind flow. Figs. 3 $\& 4$ are based on a subset of 21 strong events (extracted from the CTR and $\mathrm{CO}_{2}$ scenarios) on which the identification of the canonical maps and the correlation coefficient for the scenario simulations were based (see Section 4 for details) The analysis of the hindcast studies (Section 3) produces very similar results.

\section{VALIDATION OF THE DOWNSCALING PROCEDURE}

The downscaling procedure was applied to the T106 ERA-15 data, simulating October-December 1989-1992, which are the months during which, typically, the most intense storms take place in the Adriatic Sea.

The computation of the canonical maps and correlation coefficients was based on 7 events, representative of moderate and intense storms in the Adriatic Sea, that were simulated using the BOLAM meteorological model. The initial and boundary conditions for BOLAM were extracted from the ECMWF operational analysis. Each event is described by a sequence of maps representing the instantaneous SLP and wind fields at $6 \mathrm{~h}$ interval. More than 10 maps have been used for each event, so that the overall base for the downscaling is made of 94 maps. The 7 events were selected in order to represent high surge and wave conditions in the Adriatic Sea and aim the downscaling procedure at the reproduction of extreme events, whose intensity in a new climate scenario was the issue addressed in this study.

In order to validate the results of the downscaling, a set of simulations in which the original ERA-15 T106 winds were used was carried out and compared to the simulations forced by the downscaled wind fields. The implementation of WAM and HYPSE was identical for both sets. The results of the simulations were compared to the observations available in the Adriatic Sea, i.e. the SSE and wind speed recorded at the platform 'Aqua Alta', $15 \mathrm{~km}$ offshore in the Venetian Lagoon, and the SWH record at Pescara, on the Italian coast in the central part of the Adriatic Sea.

Fig. 5 compares the downscaled and the T106 simulations to the observations during November 1991 at the platform 'Aqua Alta'. The time series for this month is shown because of the presence of several intense events and the availability of observations. It is immediately clear that the downscaled winds achieve a significant improvement with respect to the T106 winds, but they do not fully compensate for the errors present in the simulations. The downscaled simulations generally underestimate the observations of both waves and surges, and they completely miss a few intense events.

The overall quality of the results based on the downscaled winds and T106 winds are compared in the scatter plots of Fig. 6. The scatter plots were obtained by the selection of the events characterized by high surge level or high waves, either in the observations or in the model results. The surge-level scatter plot refers to the research platform 'Aqua Alta', and the SWH scatter plot to the observations at Pescara. The threshold is $40 \mathrm{~cm}$ for the surge level and $1.5 \mathrm{~m}$ for the SWH. The maximum observed surge and wave heights reached during a storm are compared to the corresponding results for the downscaled and T106 simulations. The comparison is based on the maximum level reached during each event, without accounting for any mismatch in time. The purpose of the comparison is to evaluate not the capability of the downscaling to reproduce a specific time series, but to assess the underevaluation present in an extreme-value analysis based on the output of the downscaled fields and to show the progress that they achieve with respect to the T106 winds. The improvement obtained with the downscaling and the remaining uncompensated underestimation are quantified by the bias and the 

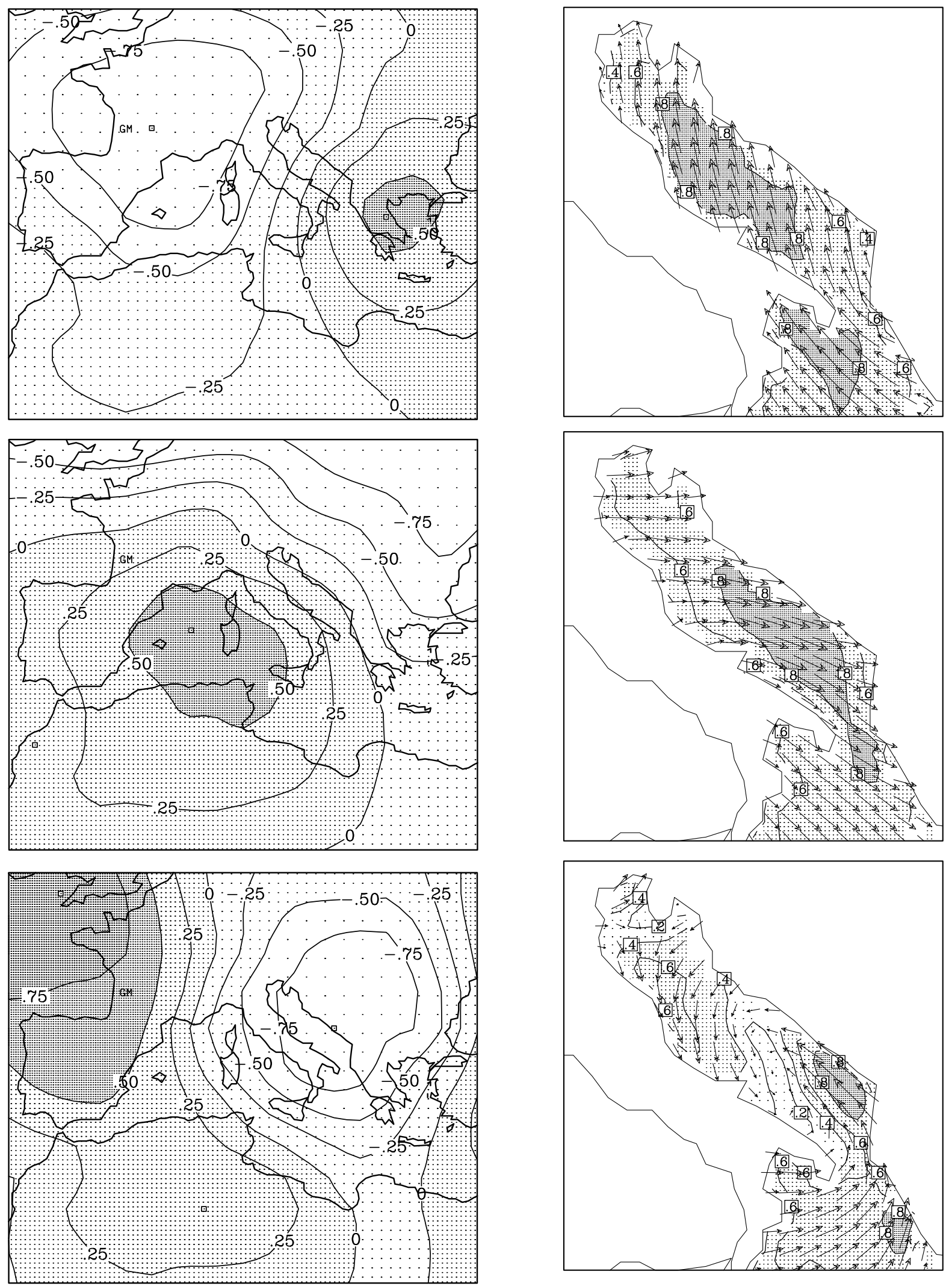

Fig. 4. First 3 canonical pairs (from top to bottom) for SLP (left column) and wind fields (right column) 

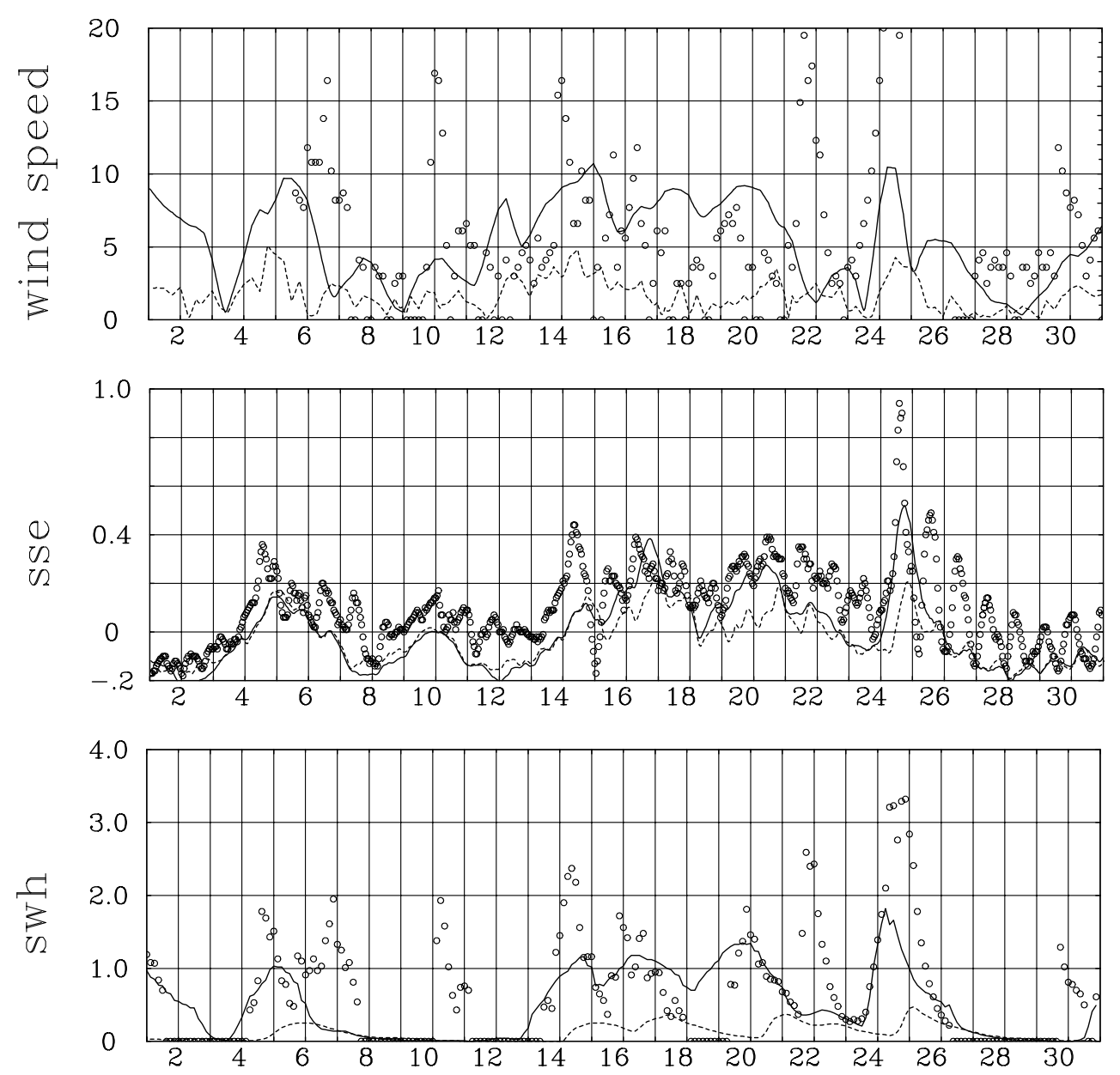

Fig. 5. Data for November 1991 at the platform 'Aqua Alta'. Top: time series of wind speed. Middle: time series of SSE; only the meteorological component (i.e. the astronomical tide was subtracted from the data) is shown. Bottom: SWH time series. Solid and dashed lines: ERA-15 downscaled and T106 winds, respectively; circles: observations

RMS error shown in Table 1, which were computed using the events shown in Fig. 6. The results show that the downscaling produces a large improvement for both surge and SWH levels. Unfortunately, a substantial, though greatly reduced, underestimation of the peak values remains, and a few strong events are absent in the model results.

Table 1. Bias and RMS error of downscaled and T106 winddriven simulations for the 4 yr long period 1989-1992. Positive bias means that the observations are larger than the model

\begin{tabular}{|c|c|c|c|c|}
\hline \multirow[t]{2}{*}{ Dataset } & \multicolumn{2}{|c|}{ Surge level $(\mathrm{cm})$} & \multicolumn{2}{|c|}{ SWH $(\mathrm{m})$} \\
\hline & Bias & RMS error & Bias & RMS error \\
\hline T106 & 38 & 43 & 1.78 & 2.02 \\
\hline Downscaling & 26 & 31 & 0.95 & 1.36 \\
\hline
\end{tabular}

\section{WAVES AND STORM-SURGE CLIMATE SCENARIOS}

In order to identify the statistical model for the climate-change study, the previously described procedure (PCA prefiltering and CCA) was applied to a subset of 21 events, 10 extracted from the CTR time-slice experiment and 11 from the $\mathrm{CO}_{2}$ time-slice experiment. The initial and boundary conditions for the regional atmospheric circulation model were extracted from the CTR and $\mathrm{CO}_{2}$ time-slice experiments. Each event has a duration of a few days, and it is represented by a sequence of instantaneous SLP and wind fields at $6 \mathrm{~h}$ intervals, so that the basis for the CCA was a total of 200 maps. The 21 events were selected by identifying deep cyclones whose tracks were likely to produce intense winds along the Adriatic Sea. The aim of the selection is the same as for the hindcasts experiments (Section 3). The sample used for the downscal- 

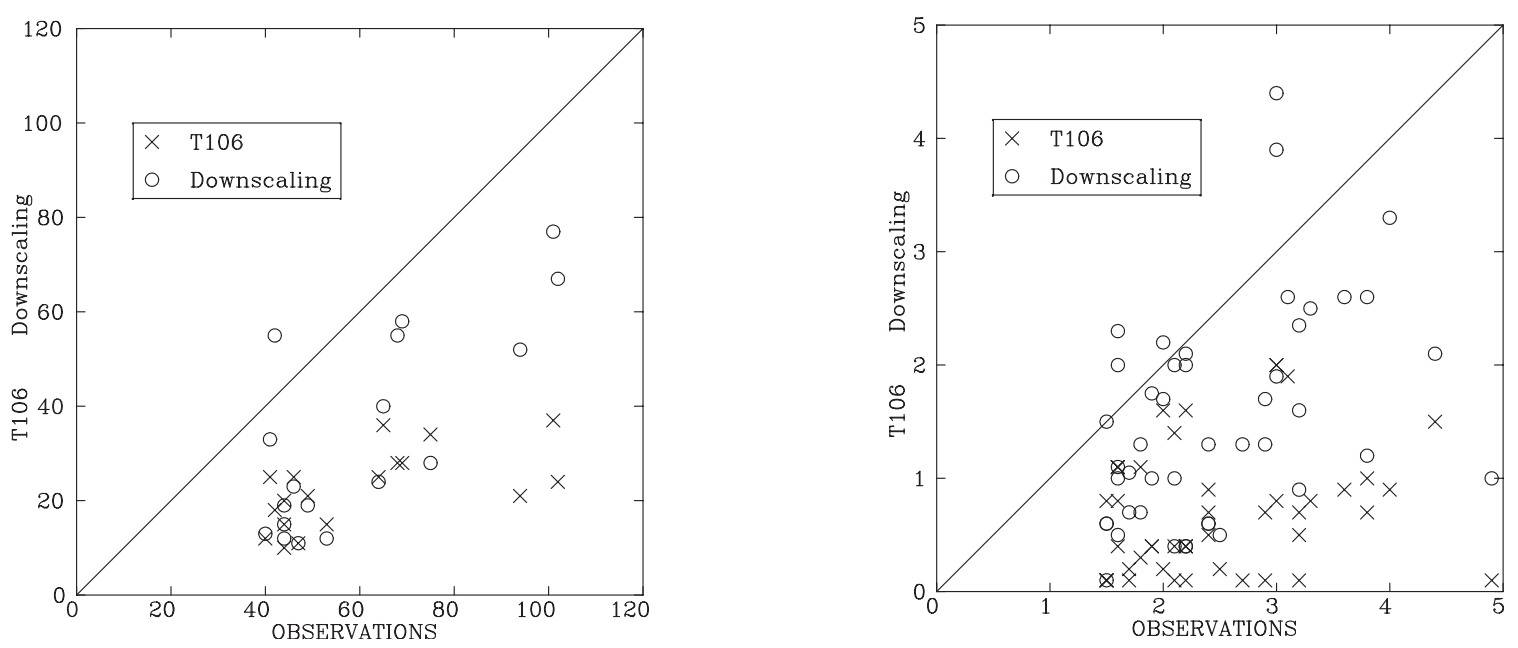

Fig. 6. Scatter plots of observations vs downscaled and T106 wind-forced simulation results. Left: SSE at 'Aqua Alta'. Right: SWH at Pescara

ing is therefore representative of the meteorological forcing characteristic of extreme events and not of weak events or of mean seasonal conditions, which were not within the scope of this study. The sample size is likely to be representative of several years of extreme events in the Adriatic Sea.

Subsequently, the statistical model was applied to the SLP fields of the CTR and the $\mathrm{CO}_{2}$ time-slice experiments, and two 30-yr long simulations were carried out for both wave fields and storm surges. The results were used for the assessment of the differences in wave and surge climates between the present and the doubled $\mathrm{CO}_{2}$ scenarios.

\subsection{Changes of the extreme values: the storm surge}

The results of the $30 \mathrm{yr} \mathrm{CTR}$ and $\mathrm{CO}_{2}$ surge simulations are summarized in Figs. 7-9. The left panels show the CTR (present climate) scenario and the right panels the $\mathrm{CO}_{2}$ scenario.

Fig. 7 shows the maximum surge level recorded in the 2 time-slice experiments. Note that the surge levels are higher and the number of events is larger in the northern shallow part of the Adriatic, where the water is accumulated by the Sirocco wind which blows along the Adriatic Sea, when a low-pressure system passes over central Europe or northern Italy. The $\mathrm{CO}_{2}$ scenario presents higher values, but the difference with respect to CTR is small. Fig. 8 shows the number of surge events above the $70 \mathrm{~cm}$ threshold. The number is very similar in the 2 scenarios. The conclusions of the analysis is that the difference between the 2 scenarios is small and that there are no indications of a significant change in the extreme surge levels.
This conclusion is confirmed by the extreme-value analysis. Fig. 9 shows the 100 yr return value of the surge level (the data were fitted to a Gumbel distribution using the maximum-likelihood method). The $\mathrm{CO}_{2}$ doubling results in a reduction that is smaller than the error of the analysis and, therefore, not significant. For both surge levels and SWH (see Section 4.2), the extreme-value analysis was based on the 2 highest events of each simulated year, that is 60 values for each scenario. Other estimates, based on sets identified using different criteria and number of events, were produced. Though the resulting extreme values were dependent on the set used, the changes were uniform in the $\mathrm{CO}_{2}$ and CTR scenarios and in the observations, the comparison thus always giving the same conclusion.

The results should be considered cautiously because of the underestimation produced by the downscaling procedure. Long time series of surge levels are available for the platform 'Aqua Alta'. An estimation of the $100 \mathrm{yr}$ surge return value was carried out on the basis of data for the period 1964-1999. The results are shown in Table 2. They confirm that the CTR simulation underestimates

Table 2. Maximum recorded and estimated 100 yr return values of the surge level at the platform 'Aqua Alta' in the CTR and $\mathrm{CO}_{2}$ experiments and in the observations

\begin{tabular}{|lcc|}
\hline & Maximum surge & 100 yr return value \\
\hline Observations & 184 & $150 \pm 8$ \\
CTR & 109 & $128 \pm 8$ \\
$\mathrm{CO}_{2}$ & 119 & $125 \pm 8$ \\
\hline
\end{tabular}



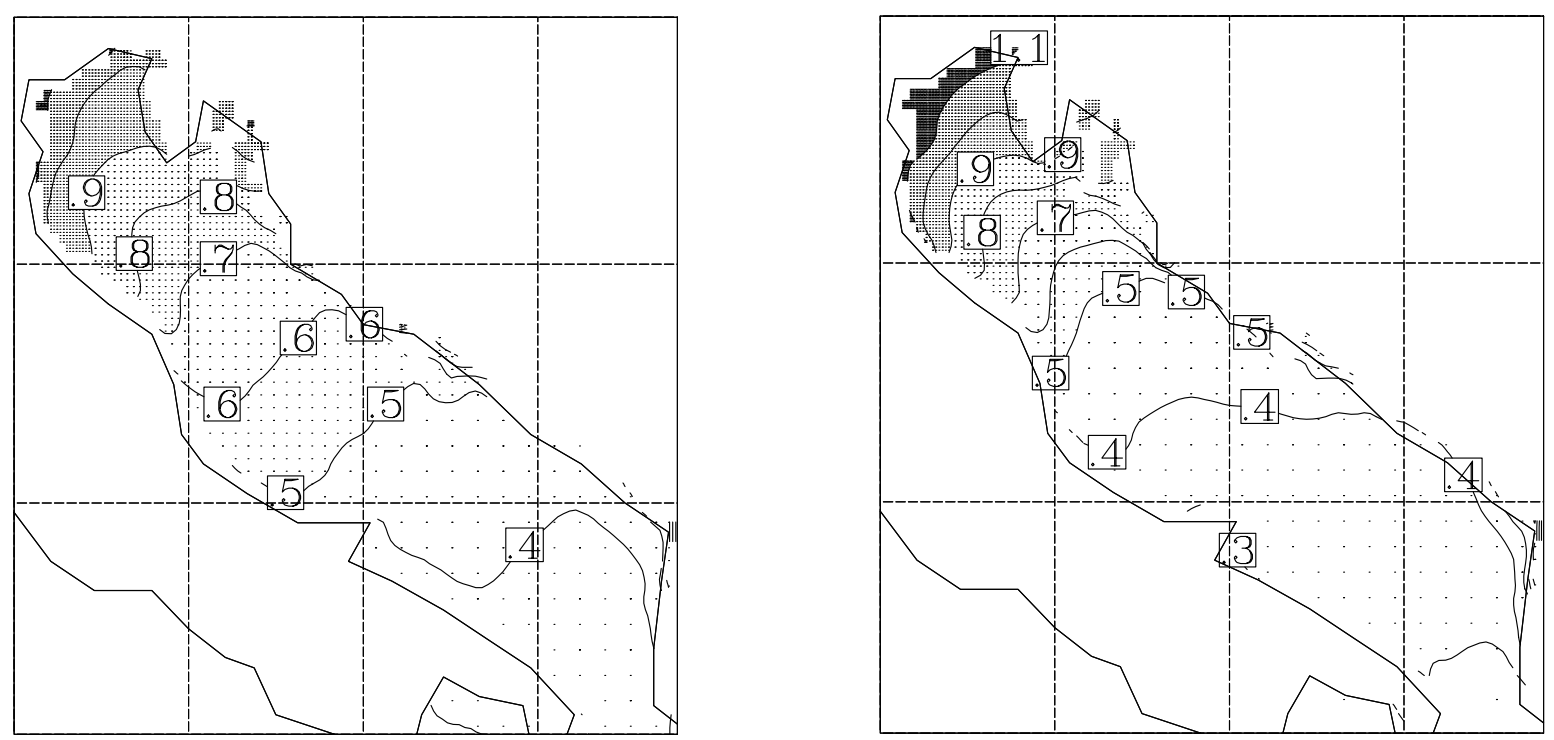

Fig. 7. Maximum surge recorded in the time-slice experiment. Model simulations of the present (left) and doubled-CO ${ }_{2}(\mathrm{right})$ climates are shown
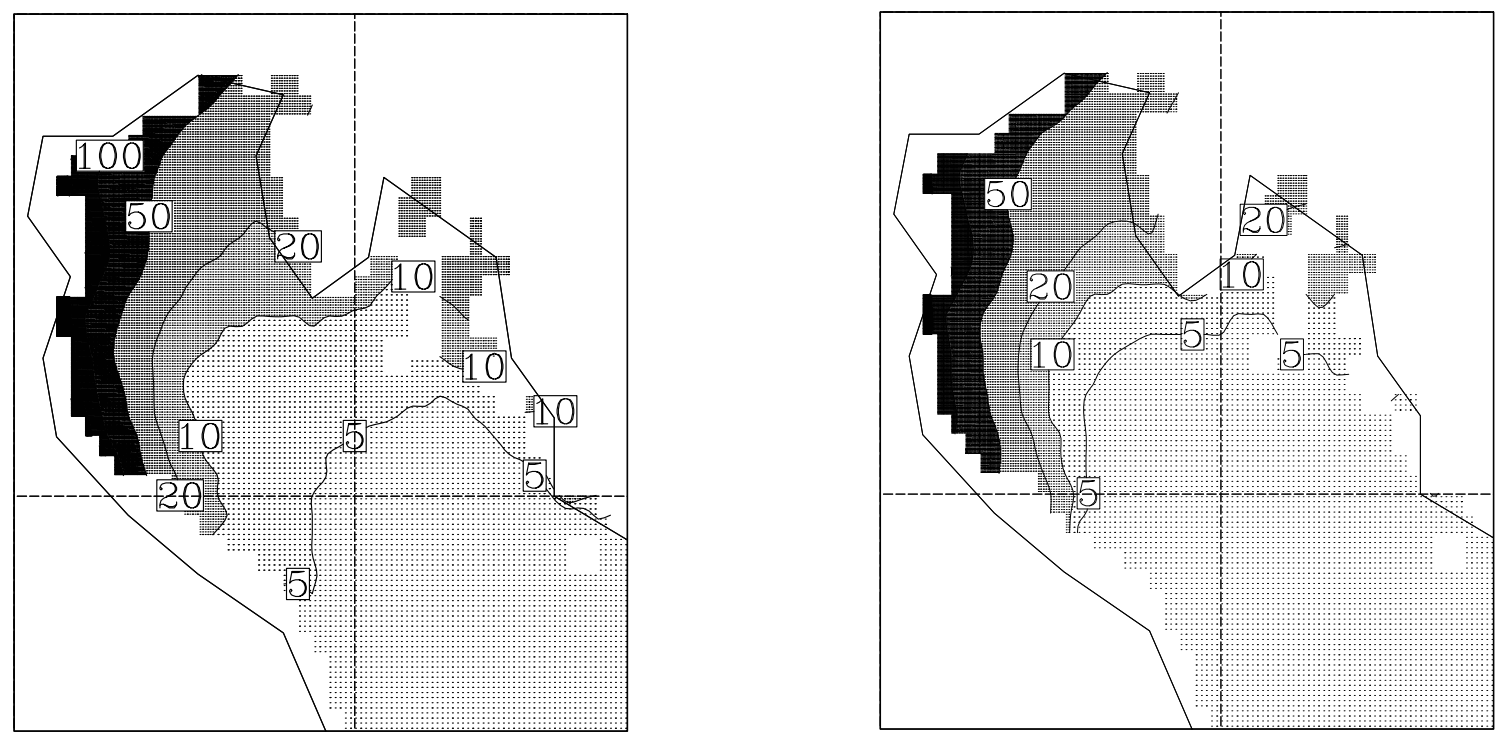

Fig. 8. Number of surge events higher than $70 \mathrm{~cm}$ recorded during the time-slice experiment. Model simulations of the present (left) and doubled- $\mathrm{CO}_{2}$ (right) climates are shown

(the error is approximately $20 \%$ ) the observed values, and that the CTR and $\mathrm{CO}_{2}$ simulations provide very similar results.

\subsection{Changes of the extreme values: the significant wave height}

The same analysis was carried out for the SWH fields. The results of the $30 \mathrm{yr} \mathrm{CTR}$ and $\mathrm{CO}_{2}$ wave simulations are summarized in Figs. 10-12. The high SWH values in the Adriatic are mainly due to the Sirocco wind (as for the high surge levels). The spatial distribution shows 2 maxima, 1 in the northern part of the basin, where the fetch is longest, and 1 in the southern part, where the wind speed is largest.

The maxima of the time-slice experiment are shown in Fig. 10, and the number of events above the $5 \mathrm{~m}$ threshold is shown in Fig. 11. Both the quantities suggest that the wave climate is milder in the $\mathrm{CO}_{2}$ scenario. The results of the extreme-value analysis (Fig. 12) also show that the $\mathrm{CO}_{2}$ doubling results in a 

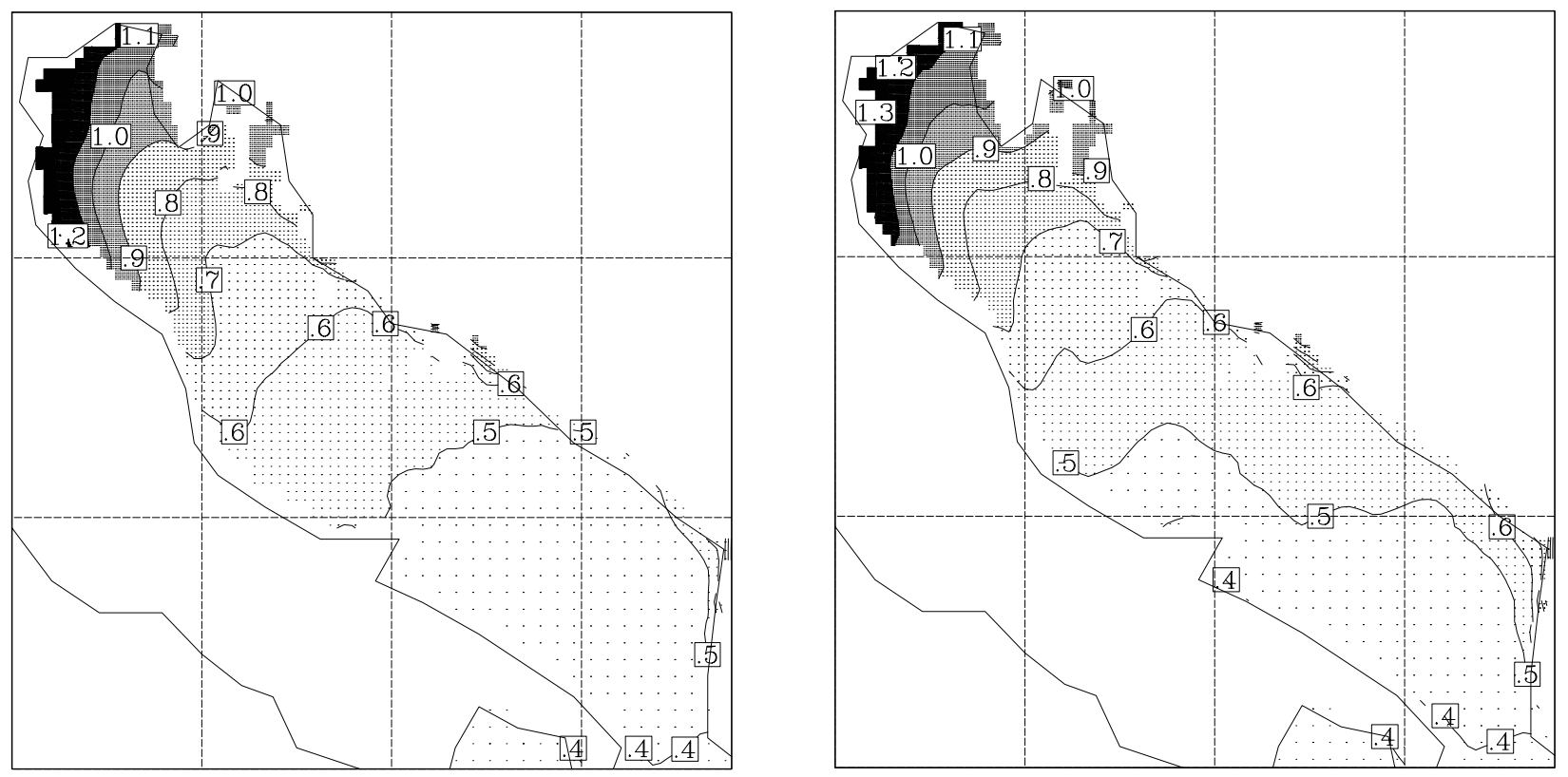

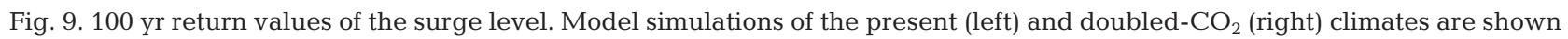

Table 3. Maximum recorded and estimated 100 yr return values of the SWH at Pescara in the $\mathrm{CTR}$ and $\mathrm{CO}_{2}$ experiments and in the observations

\begin{tabular}{|lcc|}
\hline & Maximum SWH & 100 yr return value \\
\hline Observations & 5.1 & $6.75 \pm 0.6$ \\
CTR & 5.6 & $6.1 \pm 0.4$ \\
$\mathrm{CO}_{2}$ & 4.5 & $5.6 \pm 0.3$ \\
\hline
\end{tabular}

diminished maximum expected SWH in the southern Adriatic.

The analysis of the SWH extremes brings, therefore, slightly different conclusions with respect to the analysis of the SSE extremes. This is explained by the differences between wind-velocity extremes in the 2 scenarios. Actually, this is not clear when one looks at the extremes of the wind speed (Fig. 13), which, in the southern Adriatic, is larger in the $\mathrm{CO}_{2}$ scenario. However, the SWH depends also on fetch, that is, it depends on the intensity of the Sirocco (south-easterly) wind blowing from south-east across the basin. In fact, the south-easterly component of the wind is significantly larger in the present than in the $\mathrm{CO}_{2}$ scenario (Fig. 14). This difference is important for the SWH in the southern part of the Adriatic Sea, but not relevant for the surge, which depends more on the wind value in its northern shallow part.

A systematic underevaluation of the extreme values is present also in the simulations of the SWH fields.
Observations at Pescara allow an estimate of the $100 \mathrm{yr}$ actual return value. Table 3 compares such estimates, based on 5 yr of data, to the results of this study, and it confirms the underestimation produced by the downscaling procedure that, anyway, is not very large when the value of the errors are accounted for.

\subsection{Comparison between statistical and dynamical downscaling}

An investigation was carried out to compare the results of the statistical and dynamical downscaling. The wind fields of the 21 storms used for the CCA were simulated with the tri-modular model MIAO (Model of Interacting Atmosphere and Ocean), which includes BOLAM, WAM and POM. The resolution used was $0.25^{\circ}$ for BOLAM, $16^{\circ}$ for WAM and $1 / 12^{\circ}$ for POM, that is WAM and POM adopted the same resolution used in the 30 yr CTR and $\mathrm{CO}_{2}$ experiments.

The differences between these case studies and the corresponding results of the CTR and $\mathrm{CO}_{2}$ experiments are due to the different forcing fields and to the different treatment of the southern open boundary of the Adriatic. In the case studies the sea level at the open boundary could vary according to the dynamics of the whole Mediterranean Sea and wind waves generated in the Ionian Sea could propagate inside the Adriatic. In the CTR and $\mathrm{CO}_{2}$ experiments only a small fraction of the Ionian Sea was included, and therefore, there was a strong reduction in the variability of the sea level 

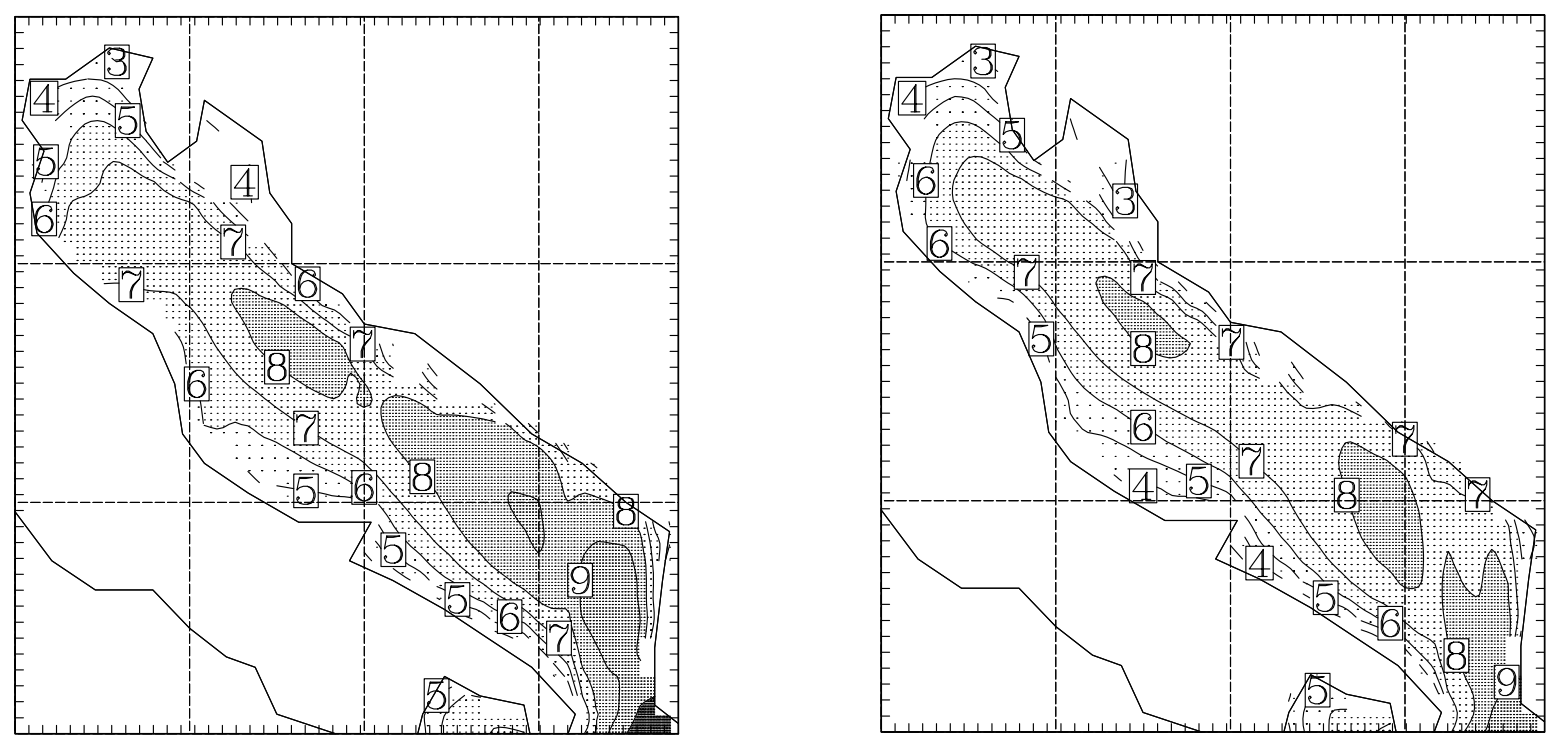

Fig. 10. Maximum SWH recorded in the time-slice experiment. Model simulations of the present (left) and doubled-CO ${ }_{2}$ (right) climates are shown
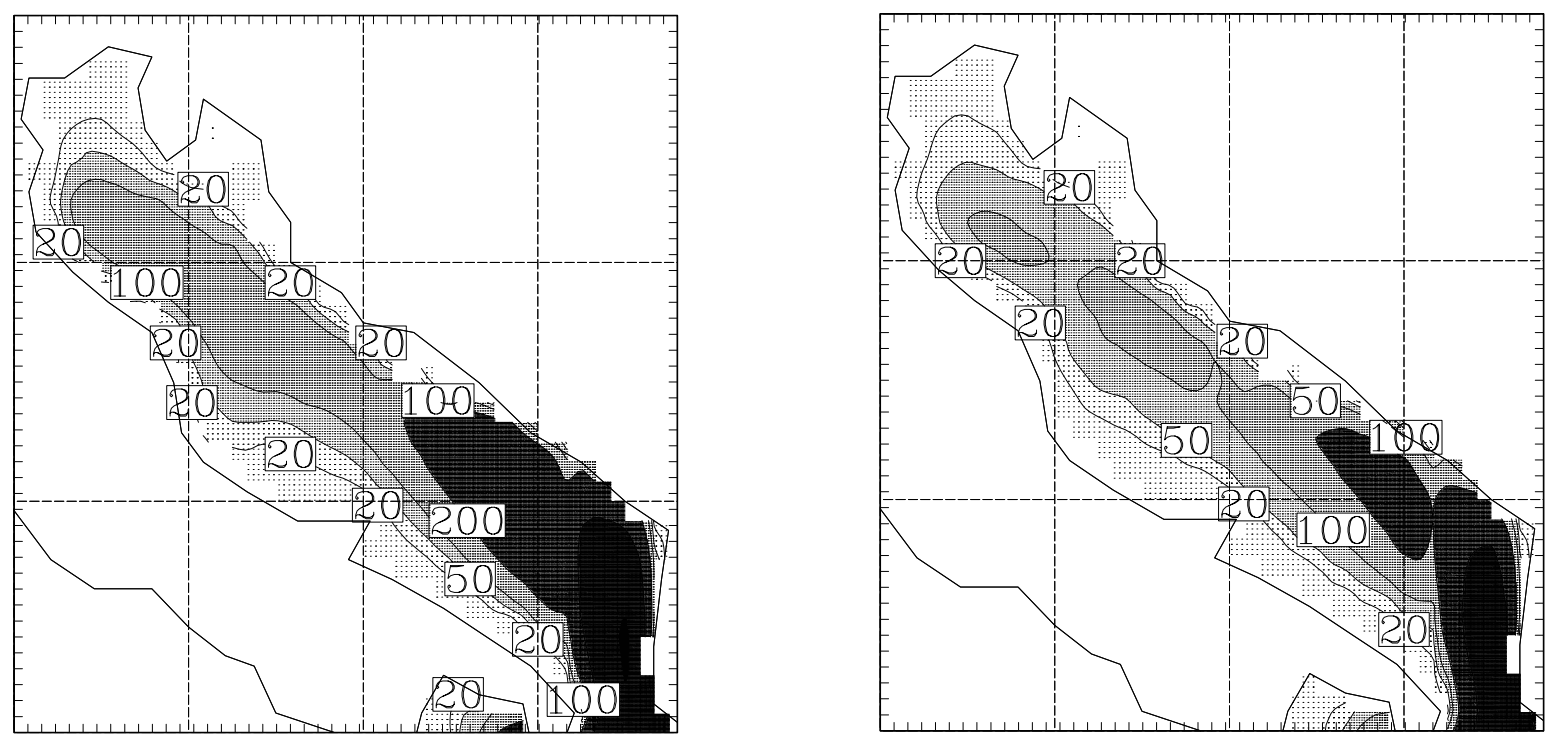

Fig. 11. Number of events with $\mathrm{SWH}$ higher than $5 \mathrm{~m}$ recorded during the time-slice experiment. Model simulations of the present (left) and doubled- $\mathrm{CO}_{2}$ (right) climates are shown

at the southern open border of the Adriatic and in the amount of wind waves propagating across it.

Actually, since the same set of storms was used for the CCA analysis, one would expect that the downscaled wind fields are very similar to the wind fields computed by BOLAM, except for the smoothing due to the PCA prefiltering and CCA analysis. This would imply, neglecting the effect of the boundary conditions, a small difference in the resulting $\mathrm{SWH}$ and surge levels. This consideration is not correct, because the time resolution of the forcing fields is necessarily $6 \mathrm{~h}$ during the CTR and $\mathrm{CO}_{2}$ experiments, where the downscaled winds are used, while it is $1 \mathrm{~h}$ during the case studies simulated with MIAO. This has large consequences for the simulation of events in the small region considered for this study. Moreover, the statistical downscaling tends to introduce a smoother time (and space) behavior of the data. Fig. 15 compares the power spectra of the wind speed at the CNR platform 'Aqua Alta' and shows the much larger amount of vari- 


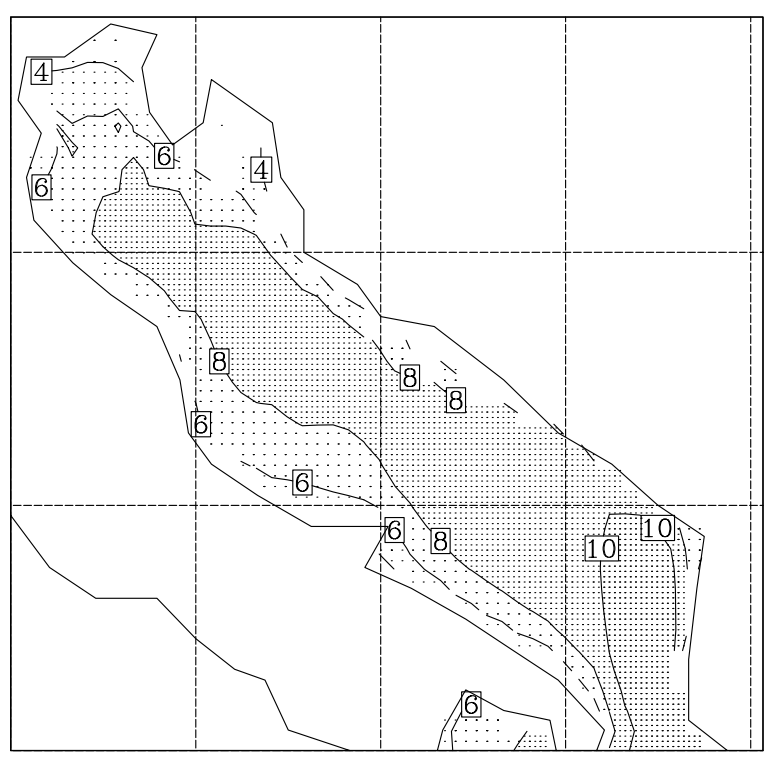

Fig. 12. 100 yr return values of SWH. Model simulations of the present (top left) and doubled- $\mathrm{CO}_{2}$ (top right) climates are shown. Bottom right: difference between the 2 scenarios (only values significantly different from zero are shown)

ability present in the dynamically downscaled fields at short time scales.

The scatter plots in Fig. 16 compare the results of the case studies to the corresponding values extracted from the $30 \mathrm{yr}$ simulations. The comparison is based on the peak values reached during each case study, which means generally a single value for each case and only occasionally 2 values when 2 events were captured in the same simulation. Moreover, a few cases were discarded, because it was evident that the length of the case study was not sufficient to reach the peak value in the Adriatic Sea. Results are somewhat disappointing, particularly for the SWH, and they show a poor agreement between statistical and dynamical downscaling. Clearly, the lack of agreement can have important
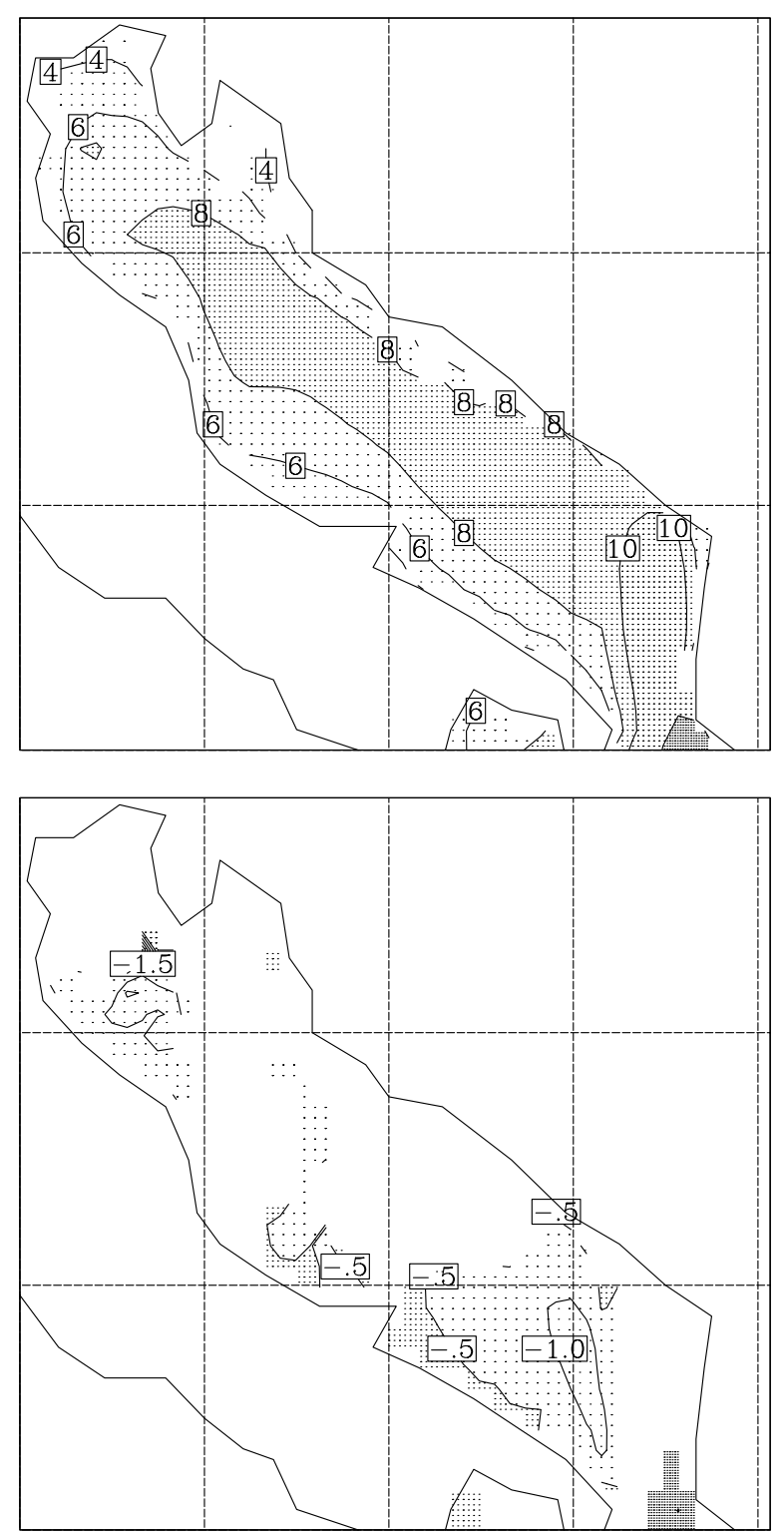

Table 4. Bias and standard deviation of the dynamical downscaling against statistical downscaling results. Positive bias means that the dynamical downscaling is higher. The analysis is based on 21 selected case studies extracted from the CTR and $\mathrm{CO}_{2}$ experiments

\begin{tabular}{|cccc|}
\hline \multicolumn{2}{|c|}{ Surge level (cm) } & \multicolumn{2}{c|}{ SWH (m) } \\
Bias & SD & Bias & SD \\
\hline 22 & 28 & 1.04 & 2.54 \\
\hline
\end{tabular}

implications for the value of the extreme events, because of the large bias between peak values obtained by statistical and dynamical downscaling (see Table 4). 

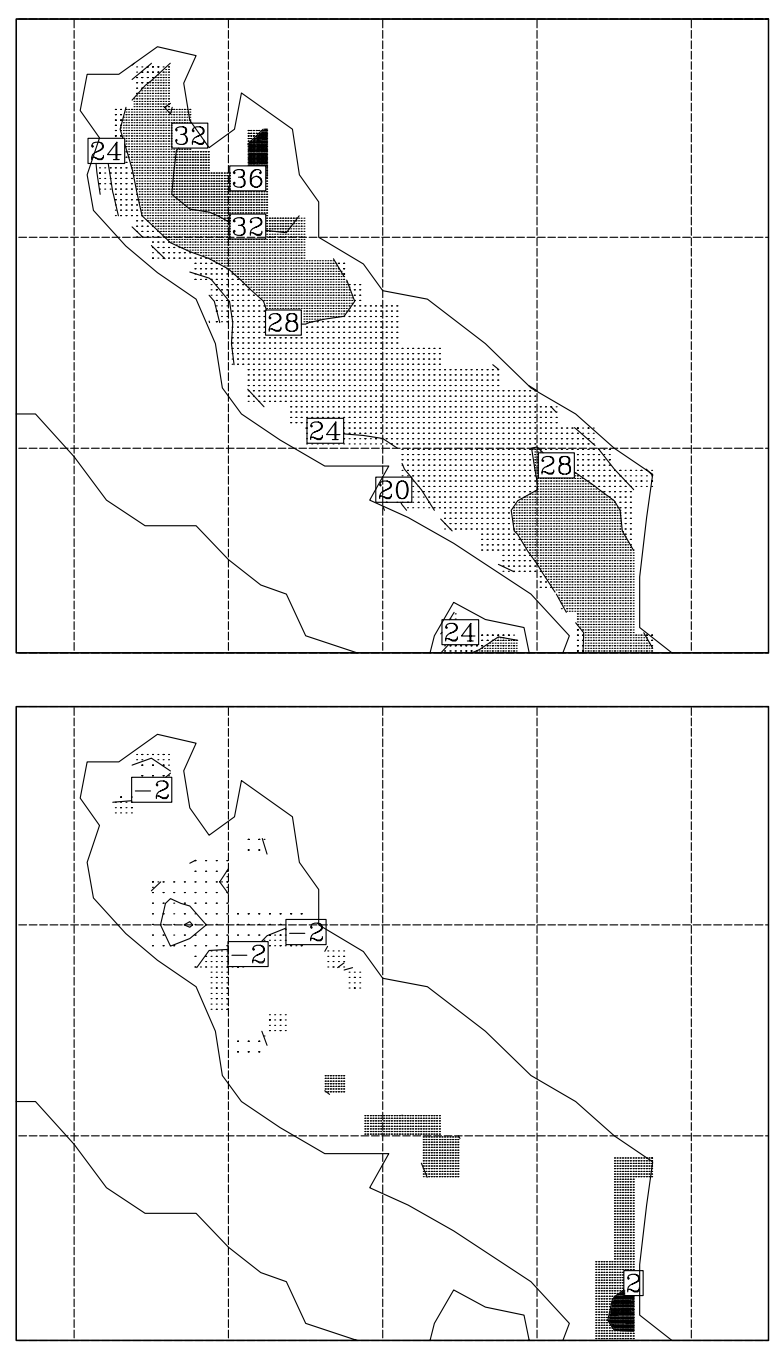

\section{DISCUSSION}

This study developed a procedure for the evaluation of climate-change scenarios for the wind waves and the storm surges at a regional scale. The procedure was applied to the Adriatic Sea, and an estimate of the effect of the doubled- $\mathrm{CO}_{2}$ atmospheric content was made.

It was shown that the global T106 simulations are not capable of describing the regional-scale wind fields that are the crucial input information needed for the computation of the wave fields and surge levels. The description of the intensification and the channeling of the wind flow along the main axis of the Adriatic by the surrounding mountain ridges requires a resolution of the order of few 10s of kilometers, which remains too high for global climate models. The direct use of the wind output from the global model, which exhibits substantially low-biased statistics, produces a large

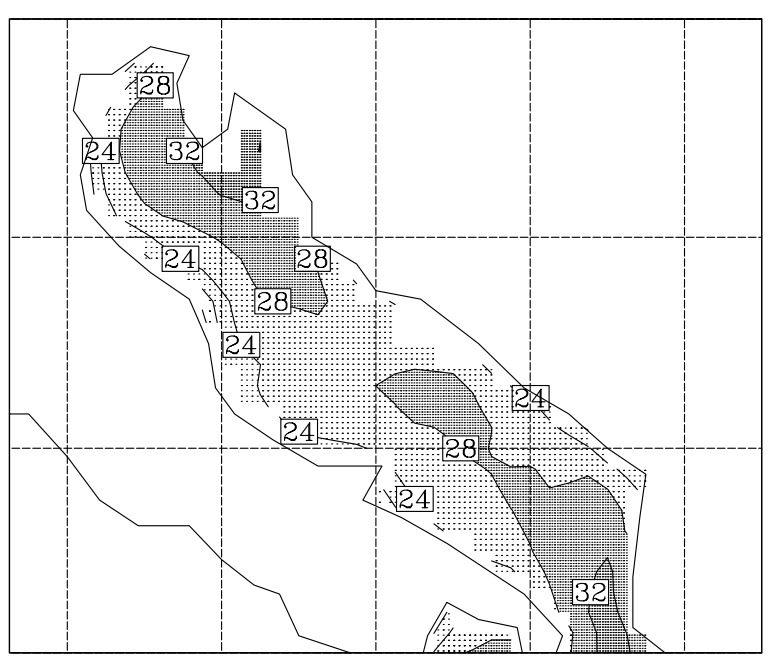

Fig. 13. $100 \mathrm{yr}$ return values of the wind speed at the $10 \mathrm{~m}$ level. Model simulations of the present (top left) and doubled$\mathrm{CO}_{2}$ (top right) climates are shown. Bottom left: difference between the 2 scenarios (only values significantly different from zero are shown)

systematic underestimation of surge levels and SWH and completely misses many important events. Therefore, applying a downscaling procedure to construct more accurate regional wind fields is necessary.

In this study, statistical downscaling was applied to obtain the regional wind fields over the Adriatic Sea at $0.25^{\circ}$ resolution from the SLP fields, computed in a time-slice experiment by a global model at T106 resolution. The procedure is based on PCA prefiltering and CCA. The high-resolution regional (Adriatic) fields were computed using a limited-area meteorological model (BOLAM) implemented over the Mediterranean region. These regional wind fields are used by the wave model WAM and a coastal ocean shallow-water model for the computation of the wave field and the storm surge, respectively.

The validity of the statistical downscaling procedure was tested by its application to the ERA-15 data in the hindcast studies. It is shown that the use of the down- 


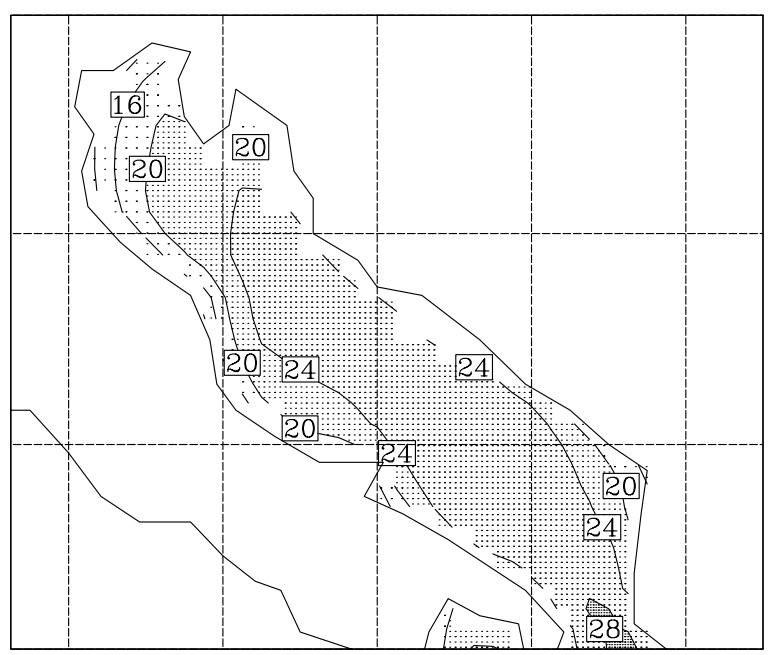

Fig. 14. $100 \mathrm{yr}$ return values of the south-easterly component of the wind speed at the $10 \mathrm{~m}$ level. Model simulations of the present (top left) and doubled- $\mathrm{CO}_{2}$ (top right) climates are shown. Bottom right: difference between the 2 scenarios (only values significantly different from zero are shown)

scaled winds greatly improves the quality of the computed wave fields and surge levels with respect to the T106 winds. Yet a substantial underestimation of both SWH and surge level remains in the results. This problem is due to the tendency of the statistical procedure to smooth the wind speed peak events, but also due to the coarse time resolution (6 h) of the SLP fields, which implies the complete absence of some intense, short duration, strong wind events in the northern Adriatic Sea. The latter problem could be avoided in future applications by saving the SLP fields with a $3 \mathrm{~h}$ time resolution, without any appreciable increase in the computing costs.

The downscaling procedure was applied to the construction of the present (CTR) and the doubled- $\mathrm{CO}_{2}$ climate scenarios for the wave fields and storm surges in the Adriatic Sea. The scenarios are derived from two 30 -yr long time-slice experiments, where the atmospheric circulation was computed on the global scale at
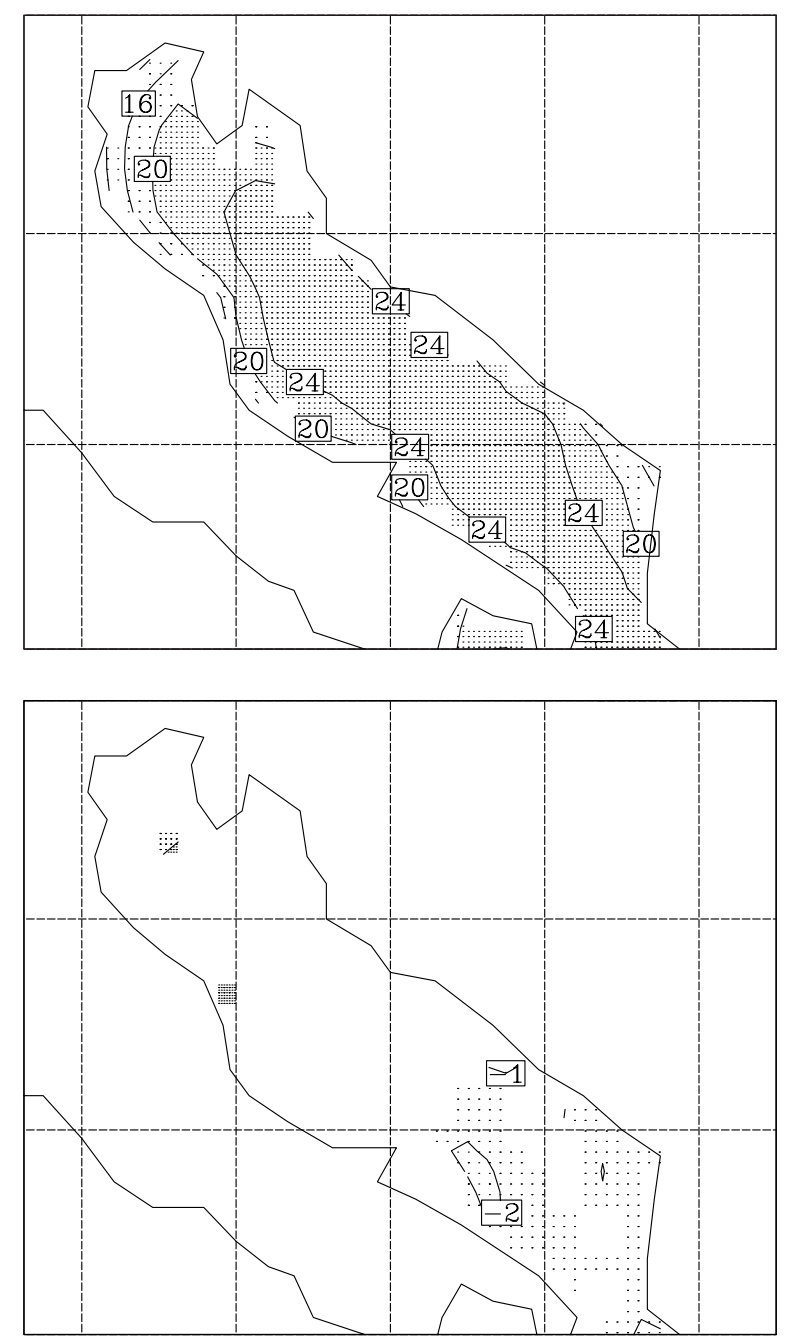

T106 resolution with the ECHAM model by the DMI. The SLP fields were used by the downscaling procedure, whose resulting SWH and SSE values were used in the extreme-value analysis that summarizes the outcome of this study. The sample used for the downscaling was deliberately restricted to extreme events. Weak events and meteorological situations not related to high wave or surge conditions were of no interest for this study, which is focused on the identification of the variations of extreme values in a doubled- $\mathrm{CO}_{2}$ scenario.

The analysis of the surge in the CTR and $\mathrm{CO}_{2}$ experiments in the Adriatic Sea shows no significant change in the intensity of the extreme events. The evaluation of the surge scenarios should be considered cautiously, because of the systematic underevaluation of surge events that is present in the CTR scenario in the Venetian littoral, where the surge has the greatest environmental impact. The comparison between the CTR scenario and the observations available in Venice shows a 


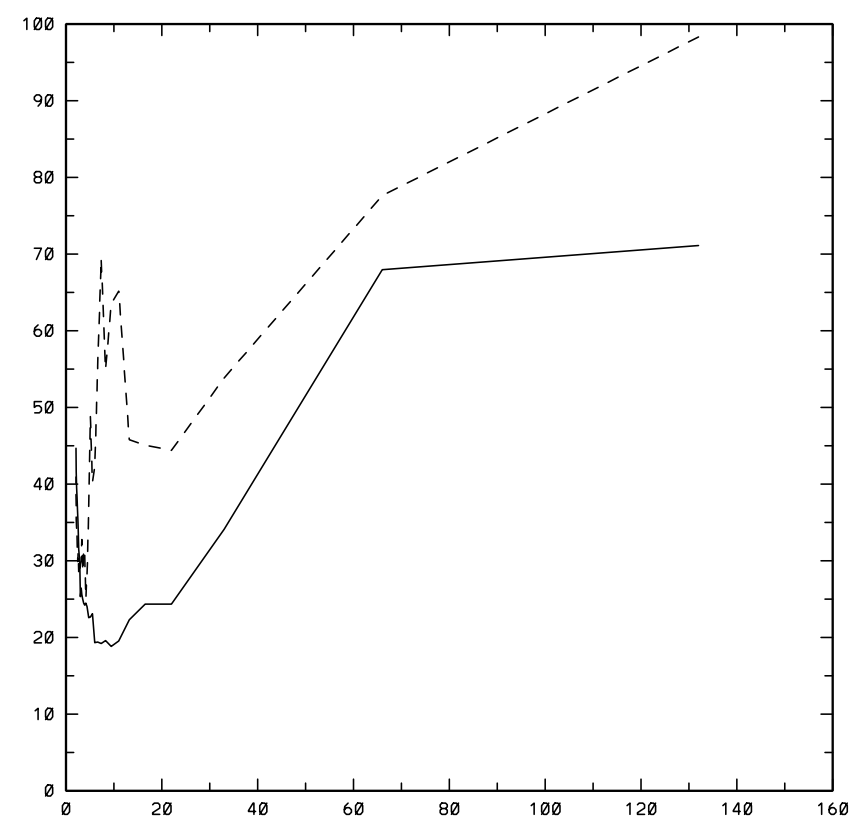

Fig. 15. Power spectra of wind speed (in $\mathrm{m}^{2} \mathrm{~s}^{-2} \mathrm{~h}^{-1}$ ) as function of period (h) at the CNR platform 'Aqua Alta' during the 21 storms used for comparing statistical (solid line) and dynamical downscaling (dashed line)

$20 \%$ underestimate of the expected 100 yr return value of the surge level. At the same time, there is no significant difference between the extreme values of CTR and $\mathrm{CO}_{2}$ scenarios.

Analysis of the wave fields confirms that the differences between the scenarios are small, but it suggests slightly different considerations, because the under- evaluation of the SWH present in the CTR scenario is smaller (approximately 10\%) and a statistically significant reduction of wave activity in the $\mathrm{CO}_{2}$ scenario was identified. This difference does not mean an inconsistency between surge levels and wave-field analysis. In fact, the surge level depends mainly on the wind fields in the northern shallow part of the Adriatic, while the wave field depends on the overall wind field, being, eventually, more sensitive to the wind values in the central and southern parts of the basin, where most wave generation takes place. The different extreme values of the south-easterly wind component in the 2 scenarios confirms this interpretation.

Selected case studies, extracted from both CTR and $\mathrm{CO}_{2}$ scenarios, were simulated with a high-resolution implementation of BOLAM, and the resulting wind fields were used to force the wave and surge models. The results were compared to the corresponding results of the statistical downscaling. The comparison shows significant differences, and it suggests that a dynamical downscaling could improve the results of the study. In fact, the statistical downscaling produced wind kinetic energy spectra lower than the dynamical downscaling. The difference is particularly large in the short-period range. The smooth temporal behavior of the wind fields produced by statistical downscaling explains the absence of seiches in the SSE, and it contributes to the final underestimation of both extreme surge and SWH values.

Though confidence in the results are undermined by the errors (a large underestimation) in the extremes in the present climate scenario, this study has shown the feasibility of an impact study focused on the effect of
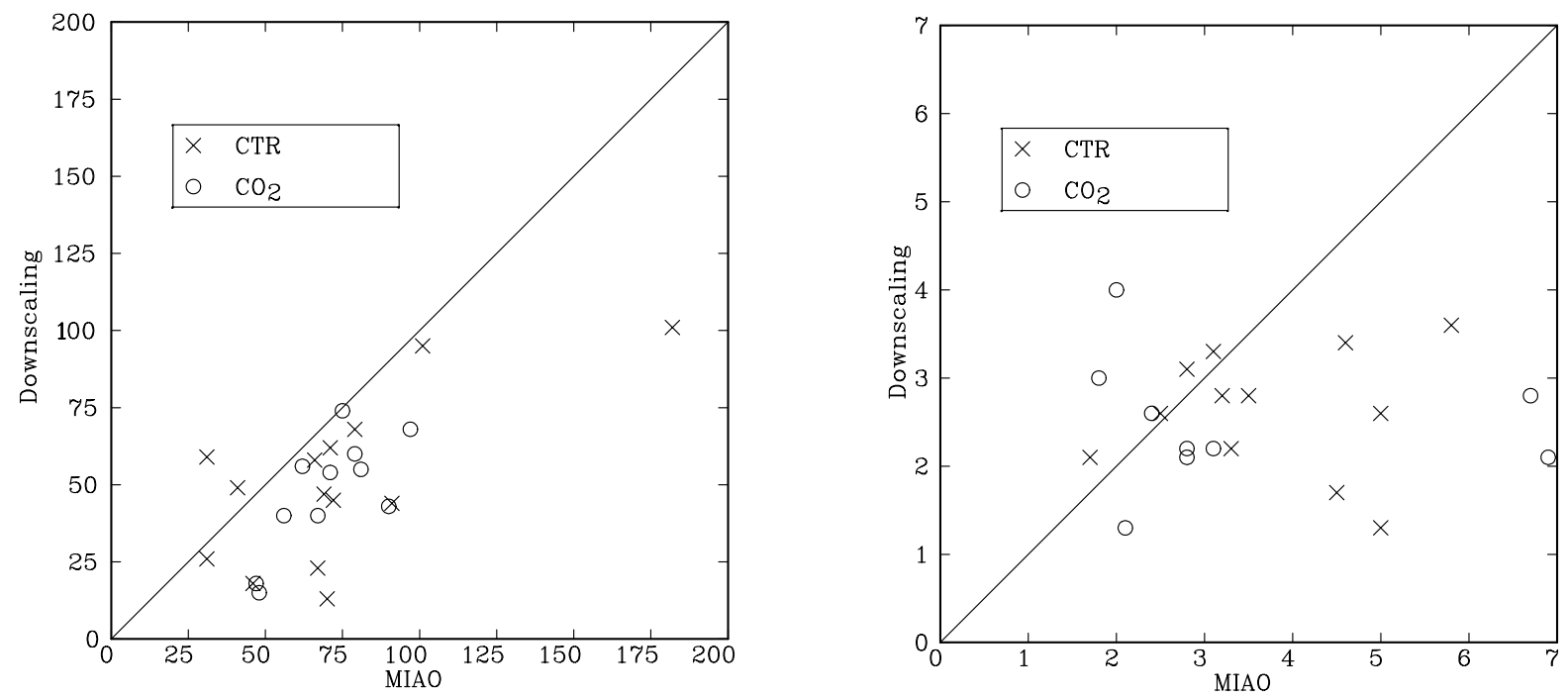

Fig. 16. Scatter plots of the high-resolution case-study results vs the downscaling results for $\mathrm{CO}_{2}$ and CTR experiments. Left: SSE at the platform 'Aqua Alta'. Right: SWH at Pescara 
the $\mathrm{CO}_{2}$ doubling on wave fields and surge levels in the Adriatic Sea. The developed approach allows us to affirm that there are no large differences in the surge and SWH extreme values between the CTR and $\mathrm{CO}_{2}$ scenarios. However, changes smaller than $10 \%$ for SWH and $20 \%$ for surge level extremes cannot be excluded because of the lack of accuracy of the downscaling procedure.

Moreover, the outcome that no large variation in the waves and surge climates in the Adriatic Sea will be produced by the $\mathrm{CO}_{2}$ doubling should be robust with respect to the downscaling approach that has been used, because it is supported by a parallel study on the variation of the cyclonic activity in the Mediterranean region (Lionello et al. 2002), which shows no large effect of the $\mathrm{CO}_{2}$ doubling. The authors analyzed the same time-slice experiments used in this study and determined the number and intensity of the cyclones in the Mediterranean region. The comparison shows no significant difference between the cyclonic activity in the CTR and $\mathrm{CO}_{2}$ scenarios. The absence of a climatechange signal in the intensity of cyclones and such an absence in the SWH and storm-surge extremes are logically consistent with one another. Obviously, both the studies could be affected by a small regional response of the ECHAM-4 model to the $\mathrm{CO}_{2}$ doubling. The analysis of this issue is not within the scope of this study. However, as far as the application of the downscaling procedure to the Adriatic Sea is concerned, we think that the absence of climate change signal is not an artifact of the downscaling procedure.

Incidentally, note that these results cannot be transferred immediately to the planning of coastal defenses, which is more complicated. Though this study points to minor variations of waves and surge climate produced by the $\mathrm{CO}_{2}$ doubling, or to an even milder climate, the effect of sea-level rise (not considered in this study) could easily convert this reassuring perspective into a dramatic situation for the management of the coastal zones of the northern Adriatic.

Editorial responsibility: Hans von Storch, Geesthacht, Germany
Acknowledgements. This study presents the results of the contribution of the University of Padua to STOWASUS-2100 (STOrms, WAves, SUrges, Scenarios in the 21st Century) of the Environment and Climate program (coordinated by E. Kaas, DMI; contract ENV4-CT97-0498). The authors are indebted to Dr R. Flather and the Proudman Oceanographic Laboratory for the program used in the extreme-value analysis. The observations used in this study were provided by Centro Previsioni Maree (SSE data), Servizi Tecnici Nazionali (SWH at Pescara) and ISDGM-CNR (SWH and wind speed at the platform 'Aqua Alta', of the Italian National Research Council, CNR).

\section{LITERATURE CITED}

Blumberg AF, Mellor GL (1987) A description of a 3-dimensional coastal ocean circulation model. In: Heaps NS (ed) 3-dim coastal ocean Models. Coastal and Estuarine Science, Vol 4, AGU, Washington, DC, p 1-16

Bretherton CS, Smith C, Wallace JM (1992) An intercomparison of methods for finding coupled patterns in climate data. J Clim 5:541-560

Buzzi AM, Fantini P, Malguzzi F, Nerozzi (1994) Validation of a limited area model in cases of Mediterranean cyclogenesis: surface fields and precipitation scores. Meteorol Atmos Phys 53:137-153

Gibson R, Kålberg P, Uppala S (1996) The ECMWF ReAnalysis (ERA) project. ECMWF Newsl 73:7-17

IPCC (1994) Climate change 1994-radiative forcing of climate change and an evaluation of the IPCC92 scenarios. Cambridge University Press, Cambridge

May W (1999) A time slice experiment with the ECHAM4GCM model at high resolution: the experimental design and the assessment of the climate change as compared to a greenhouse gas experiment with ECHAM4/OPYC at low resolution. Danish Meteorological Institute, Lyngbyvej, Copenhagen, Scientific Report 99-2

Lionello P, Zampato L, Malguzzi P, Tomasin A, Bergamasco A (1998) On the correct surface stress for the prediction of the wind wave field and the storm surge in the northern Adriatic Sea. Nuovo Cimento C 21:515-532

Lionello P, Elvini E, Dalan F (2002) Cyclones in the Mediterranean region: the present and the doubled $\mathrm{CO}_{2}$ climate scenarios. Clim Res 22:147-159

WAMDI Group (Hasselmann S, Hasselmann K, Bauer E, Janssen PAEM and 9 others) (1988) The WAM model-a third generation ocean wave prediction model. J Phys Oceanogr 18:1776-1810

Submitted: October 5, 2001; Accepted: October 26, 2002 Proofs received from author(s): February 20, 2003 